\title{
THE FIBRINOLYTIC ALTERATION ASSOCIATED WITH DAILY ADMINISTRATION OF SILDENAFIL
}

\author{
FATHELRAHMAN M HASSAN* \\ Department of Clinical Laboratory Science, College of Applied Medical Science, Immam Abdulrahman Bin Faisal University, Dammam, \\ Saudi Arabia. Email: fathmaga@yahoo.com
}

Received: 16 October 2017, Revised and Accepted: 21 April 2018

\begin{abstract}
Objective: The objective of this study was to determine the fibrinolytic alteration associated with daily administration of sildenafil.

Methods: A total of 12 adult male rabbits without mortality rate had been fed standard and subdivided into four groups; their average weight was $1.5,2.5,1.9$, and $2 \mathrm{~kg}$ randomly selected during the period of March 2012-July 2013. Depending on weight, the control groups (2.25 mg/1.5 kg day) and sildenafil groups ( $3 \mathrm{mg} / 2 \mathrm{~kg} /$ day, $2.85 \mathrm{mg} / 1.9 \mathrm{~kg} /$ day, and $1.7 \mathrm{mg} / 2.5 \mathrm{~kg} /$ day) were injected by normal saline and sildenafil concentration, respectively to create four groups, every group was composed of three rabbits; saline rabbit (control group, $\mathrm{n}=3$ ) and sildenafil rabbits (sildenafil group, $n=9$ ). All rabbit's plasma samples have been investigated for prothrombin time, activated partial thromboplastin time, fibrinogen, plasminogen activator inhibitor-1 (PAI-1), prothrombin fragment 1+2, tissues plasminogen activator (tPA), plasmin antiplasmin (PAP), plasminogen, and D-dimer
\end{abstract} after $24 \mathrm{~h}$ of administration.

Results: The PAP level was significantly $(\mathrm{p}<0.05)$ decreased following sildenafil injection. Sildenafil-injected $(3 \mathrm{mg} / \mathrm{ml}) \mathrm{rabbits}$ had decreased the means of PAI-1 and mean tPA, as early as 1-day post-injection, with a considerable lower PAP first determined 3 days after injection that continued into each rabbit 2 and 3.

Conclusion: Better strategies are to initiate and manipulate this drug ought to reduce the chance of each thrombosis and hemorrhage, at the same time as minimizing the need for laboratory monitoring with the aid of the use of PAI-1, tPA, and PAP checks.

Keywords: Fibrinolytic, Alteration, Administration, Sildenafil.

(C) 2018 The Authors. Published by Innovare Academic Sciences Pvt Ltd. This is an open access article under the CC BY license (http://creativecommons. org/licenses/by/4. 0/) DOI: http://dx.doi.org/10.22159/ajpcr.2018.v11i8.23144

\section{INTRODUCTION}

Clinical studies support the use of sildenafil as a treatment for various forms of pulmonary arterial hypertension in both children and adults $[1,2]$ and for prevention or management of the right heart failure $[3,4]$. The observation of an antiplatelet effect of sildenafil and its influence in improving the microcirculation during wound healing in animal and human studies has also been encouraging [5-7]. Other animals and clinical studies have tested capability advantages of sildenafil in situations associated with diminished skin blood go with the flow and bad vascularization, which includes Raynaud's phenomenon and virtual ulcers in patients with systemic sclerosis [8-11]. Different studies have shown beneficial effects of low doses of sildenafil on portopulmonary hypertension following liver transplantation [12] or on systemic sclerosis associated with pulmonary hypertension [13]. Data from animal models on the beneficial effects of sildenafil on wound healing are promising, but human data are currently lacking [14]. Several research studies have been focused on different effects of sildenafil on tissue repair, but the alteration in fibrinolysis pathway associate to vascular defect was not done before. In the present study, the impact of sildenafil on wound healing in all clinical experimental is discussed by determining fibrinolytic alteration associated with daily administration of sildenafil.

\section{METHODS}

All experiments were authorized using the animal coverage committee of the College of Applied Medical Science, Aljouf University. 12 adult male rabbits without mortality rate had been fed standard and subdivided into four groups; their average weight was $1.5,2.5,1.9$, and $2 \mathrm{~kg}$, respectively, and randomly selected during the period of March 2012-July 2013. Depending on weight, the control groups $(2.25 \mathrm{mg} / 1.5 \mathrm{~kg} /$ day $)$ and sildenafil groups $(1.7 \mathrm{mg} / 2.5 \mathrm{~kg} /$ day, $2.85 \mathrm{mg} / 1.9 \mathrm{~kg} /$ day, and $3 \mathrm{mg} / 2 \mathrm{~kg} /$ day) were injected by normal saline and sildenafil concentration, every group was composed of three rabbits; saline rabbit (control group, $n=3$ ) and sildenafil rabbits (sildenafil group, $\mathrm{n}=9$ ). About $1-1.5 \mathrm{ml}$ of blood was collected from each animal by aspirated from the ear or thigh vein according to the clarity of the vein and added to the anticoagulant $(3.2 \%, 0.105 \mathrm{M})$ buffered sodium citrate, then gently mixed. The samples were centrifuged at $1700 \mathrm{~g}$ for $15 \mathrm{~min}$ to obtain plateletpoor plasma. We consequently used the higher dosage $(3 \mathrm{mg} / \mathrm{ml})$ to examine the consequences of treatment on fibrinolytic feature caused using sildenafil overdose as these results were greater obvious with the more extreme fibrinolytic alteration caused using the better dosage. All rabbit's plasma samples have been investigated for prothrombin time, fibrinogen, plasminogen activator inhibitor-1 (PAI-1), prothrombin fragment $1+2$, tissues plasminogen activator (tPA), plasmin antiplasmin (PAP), plasminogen, and D-dimer (DD) after $24 \mathrm{~h}$ of administration. The statistical software SPSS 17 for windows was used for data analysis. Statistics is provided as mean \pm standard deviation. Differences between groups were analyzed through one-way ANOVA test for more than one comparison, with a probability value $\mathrm{p}<0.05$ appeared as significant.

\section{RESULTS AND DISCUSSION}

To establish a time path of sildenafil - brought on fibrinolytic alteration, we tested rabbits 1-3 days after injection with sildenafil and compared them to saline-injected control animals that have been examined on the primary day of the check. When compared sildenafil-injected groups to these controls, two rabbits out of 12 had been died after completing this step. The purpose of death may be due to hypovolemia as approximately 
1-1.5 ml of blood was aspirated. The laboratory data were analyzed statistically for the level of significant. Table 1 summarizes that there was a significant difference $(\mathrm{p}<0.05)$ between the post-operative activated partial thromboplastin time (APTT) and the APTT control.

The PAP level was significantly $(\mathrm{p}<0.05)$ decreased following sildenafil injection as shown in Tables 2 and 3. Sildenafil-injected ( $3 \mathrm{mg} / \mathrm{ml}$ ) rabbits had decreased the means of PAI-1 and mean tPA, as early as 1-day post-injection, with a significant decrease PAP first observed 3 days after injection that continued into both rabbits 2 and 3 .

Table 1: Fibrinolytic and clotting parameters in rabbits Group-1 injected by sildenafil $(1.7 \mathrm{mg} / \mathrm{ml})$

\begin{tabular}{llll}
\hline Variables & \multicolumn{2}{c}{ Mean \pm SD } & p \\
\cline { 2 - 3 } & Group-1 & Control & \\
\hline PT Sec. & $14.0 \pm 2.3$ & $11.0 \pm 2.3$ & 0.400 \\
APTT Sec. & $32.0 \pm 2.1$ & $26.0 \pm 2.2$ & $0.020^{*}$ \\
FIB (g/l) & $3.6 \pm 1.90$ & $3.1 \pm 1.50$ & 0.700 \\
PAI-1 (ng/ml) & $0.44 \pm 0.10$ & $0.45 \pm 0.02$ & 0.800 \\
F1+2 (ng/ml) & $75.9 \pm 17.7$ & $73.9 \pm 19.3$ & 0.910 \\
tPA (ng/ml) & $9.1 \pm 3.70$ & $10.2 \pm 3.80$ & 0.780 \\
PAP (ng/ml) & $96.6 \pm 5.30$ & $91.6 \pm 3.30$ & 0.240 \\
DD (ng/ml) & $346.9 \pm 22.1$ & $342.5 \pm 24.1$ & 0.830 \\
\hline
\end{tabular}

${ }^{*} \mathrm{p}<0.05$ is statistically significant, Sec.: Seconds. PT: Prothrombin time, APTT: Activated partial thromboplastin time, FIB: Fibrinogen, PAI-1: Plasminogen activator inhibitor-1, F1+2: Fragment 1+2, tPA: Tissues plasminogen activator, PAP: Plasmin antiplasmin, DD: D-dimer, SD: Standard deviation

Table 2: Fibrinolytic and clotting parameters in rabbits' Group-2 injected by sildenafil $(2.85 \mathrm{mg} / \mathrm{ml})$

\begin{tabular}{llll}
\hline Variables & \multicolumn{2}{c}{ Mean \pm SD } & p \\
\cline { 2 - 3 } & Group-2 & Control & \\
\hline PT Sec. & $14.0 \pm 2.2$ & $11.0 \pm 2.3$ & 0.200 \\
APTT Sec. & $28.0 \pm 2.3$ & $26.0 \pm 2.2$ & 0.300 \\
FIB (g/l) & $3.2 \pm 1.8$ & $3.1 \pm 1.5$ & 0.900 \\
PAI-1 (ng/ml) & $0.42 \pm 0.2$ & $0.45 \pm 0.02$ & 0.800 \\
F1+2 (ng/ml) & $74.8 \pm 23.5$ & $73.9 \pm 19.3$ & 0.900 \\
tPA (ng/ml) & $5.2 \pm 1.3$ & $10.2 \pm 3.8$ & 0.090 \\
PAP (ng/ml) & $55.8 \pm 3.1$ & $91.6 \pm 3.3$ & $0.000^{*}$ \\
DD (ng/ml) & $361.4 \pm 43.5$ & $342.5 \pm 24.1$ & 0.500 \\
\hline
\end{tabular}

${ }^{*} \mathrm{p}<0.05$ is statistically significant. PT: Prothrombin time, APTT: Activated partial thromboplastin time, FIB: Fibrinogen, PAI-1: Plasminogen activator inhibitor-1, F1+2: Fragment 1+2, tPA: Tissues plasminogen activator

PAP: Plasmin antiplasmin, DD: D-dimer, SD: Standard deviation

Table 3: Fibrinolytic and clotting parameters in rabbits - 3 injected by sildenafil ( $3 \mathrm{mg} / \mathrm{ml})$

\begin{tabular}{llll}
\hline Variables & \multicolumn{2}{l}{ Mean \pm SD } & p \\
\cline { 2 - 3 } & Group-3 & Control & \\
\hline PT Sec. & $12.0 \pm 2.3$ & $11.0 \pm 2.3$ & 0.600 \\
APTT Sec. & $30.0 \pm 2.1$ & $26.0 \pm 2.2$ & 0.080 \\
FIB (g/l) & $3.6 \pm 1.9$ & $3.1 \pm 1.5$ & 0.700 \\
PAI-1 (ng/ml) & $0.40 \pm 0.10$ & $0.45 \pm 0.02$ & 0.440 \\
F1+2 (ng/ml) & $78.9 \pm 17.7$ & $73.9 \pm 19.3$ & 0.750 \\
tPA (ng/ml) & $8.1 \pm 6.70$ & $10.2 \pm 3.8$ & 0.660 \\
PAP (ng/ml) & $51.6 \pm 5.3$ & $91.6 \pm 3.3$ & $0.000^{*}$ \\
DD (ng/ml) & $371.9 \pm 22.1$ & $342.5 \pm 24.1$ & 0.190 \\
\hline
\end{tabular}

${ }^{*} \mathrm{p}<0.05$ is statistically significant. PT: Prothrombin time, APTT: Activated partial thromboplastin time, FIB: Fibrinogen, PAI-1: Plasminogen activator inhibitor-1, F1+2: Fragment 1+2, tPA: Tissues plasminogen activator, PAP: Plasmin antiplasmin, DD: D-dimer, SD: Standard deviation
This study has shown that systemic administration of sildenafil injected has a significant difference $(p<0.05)$ in reduces altered fibrinolytic and clotting parameters and had a controlling effect on function which did not achieve significance in a group of 12 rabbits. To maintain the fibrinolytic and clotting parameters within the therapeutic level we have to reduce of sildenafil dose for 2-3 days period; hence, acute clinical signs and symptoms required emergency [15]. PAI-1, tPA, and PAP were essential laboratory screening for monitoring of sildenafil since decreased of such more than the therapeutic level reflects a bleeding tendency. In the present study, systemic administration of sildenafil on rabbits injected with sildenafil showed that significant differences in reducing some parameter levels to nearly to the control level. These results agreed with those who used sildenafil to control of with diminished skin blood flow without with fibrinolysis change. Without fibrinolysis change. In addition to the cases of hereditary coagulation defect as haemophiliac patients factor VIII deficiency. The use of sildenafil administered either as hemorrhage reduction in patients with coagulation disorders [16].

Numerous preceding research has advised that the high negative predictive value of DD testing in outpatients with suspected thrombosis may be used as part of a diagnostic set of rules $[17,18]$. The value of mixing medical estimation of possibility with imaging assessments has been confirmed in different research [19]. We and others have proven the capability for the use of those checking out to simplify analysis further and showed the use of sildenafil within the treatment of erectile disorder and pulmonary arterial high blood pressure in which it relaxes the arterial wall and reduced pulmonary arterial resistance and pressure [20,21]. However, none of these strategies have previously been as compared in a randomized trial We have to demonstrate PAI-1, tPA, and PAP testing to rule out sildenafil overdose advantages from the other clinical conditions. The regular of some effects in rabbits might also need for a repeated take a look with high quality. This method has the extra advantage of increasing the percentage of rabbits may have an effective result on the repeated test. In the end, our effects are probably to be valid due to the fact the look at challenge was randomized, and the consequences had been determined by blinded to the rabbit assignments after sildenafil overdose.

Our observation was confirmed by previous medical study for the diagnosis of thrombosis, in which categorized rabbits into high, moderate, and low and others that not going to have thrombosis [22]. The addition to the scoring gadget of one factor for a preceding diagnosis of thrombosis lets to be used in previous thrombosis set. Therefore, we had excluded from earlier studies and evaluated the affected rabbits depending on the given results of previous test; our technique might be to be safe in sildenafil overdose; however, validation studies are required [23]. The use of these assays may be taken into consideration a challenge. However, the assay has some accuracy. We consequently consider our diagnostic strategy has to work regardless, of which the assay is used, provided that the assay selected has a sensitivity and specificity [24]. In comparison with previous studies that examined the relation of fibrinolytic and clotting parameters that related to sildenafil overdose, this study has the benefit of fibrinolytic imbalance and a statistical model that better addresses known confounders [25] which was in agreement with Eguchi et al. who demonstrated that endothelial cell mitochondria has decisive role on thrombus formation process $[26,27]$

\section{CONCLUSION}

In rabbits with active, major bleeding, plasma, in combination intravenous sildenafil overdose should be given and quickly reduces the dose in which may be discontinued temporarily or permanently. As during the initiation of sildenafil, the fibrinolytic activity in the period immediately after sildenafil is discontinued may not accurately reflect the degree of impairment of coagulation. A single intravenous dose of $2.5 \mathrm{mg} / 2 \mathrm{Kg}$ sildenafil given preoperatively was effective in 
reducing post-operative fibrinolytic and clotting parameters. Sildenafil overdose remained the mainstay of a rise of thrombotic. Better techniques to initiate and manage this drug must reduce the chance of each thrombosis and hemorrhage, at the same time as minimizing the want for laboratory tracking using PAI-1, tPA, and PAP examinations. Effective techniques for the treatment of bleeding ought to simplify the care of sildenafil overdose, reduce the long-time period morbidity resulting from hemorrhage and probably risky.

\section{AUTHOR'S CONTRIBUTIONS}

All the authors have contributed equally.

\section{CONFLICTS OF INTEREST}

The authors declare that they have no conflicts of interest.

\section{REFERENCES}

1. Sastry B, Narasimhan C, Reddy N, Anand B, Prakash G, Raju PR, et al. A study of clinical efficacy of sildenafil in patients with primary pulmonary hypertension. Indian Heart J 2002;54:410-4.

2. Sastry B, Narasimhan C, Reddy NK, Raju BS. Clinical efficacy of sildenafil in primary pulmonary hypertension: A randomized, placebo-controlled, double-blind, crossover study. J Am Coll Cardiol 2004;43:1149-53.

3. Chen YJ, Traverse JH, Hou M, Li Y, Du R, Bache RJ. Effect of PDE5 inhibition on coronary hemodynamics in pacing-induced heart failure. Am J Physiol Heart Circ Physiol 2003;284:H1513-20

4. Fischer T, Erbel R, Treese N. Current status of phosphodiesterase inhibitors in the treatment of congestive heart failure. Drugs 1992;44:928-45.

5. Ulusoy MG, Uysal A, Koãer U, Karaaslan Ã, Cuzdan SS, Ayyldz A, et al. Improved flap viability with site-specific delivery of sildenafil citrate using fibrin glue. Ann Plastic Surg 2005;55:292.

6. Sarifakioglu N, Gokrem S, Ates L, Akbuga UB, Aslan G. The influence of sildenafil on random skin flap survival in rats: An experimental study. Br J Plast Surg 2004;57:769-72.

7. Li Z, Xi X, Gu M, Feil R, Ye RD, Eigenthaler M, et al. A stimulatory role for cGMP-dependent protein kinase in platelet activation. Cell 2003;112:77-86.

8. Gore J, Silver R. Oral sildenafil for the treatment of Raynaud's phenomenon and digital ulcers secondary to systemic sclerosis. Ann Rheum Dis 2005;64:1387.

9. Ambach A, Seo W, Bonnekoh B, Gollnick H. Lowdose combination therapy of severe digital ulcers in diffuse progressive systemic sclerosis with the endothelin-1 receptor antagonist bosentan and the phosphodiesterase V inhibitor sildenafil. J Dtsch Dermatol Ges 2009; 7:888-91.

10. Chung L. Therapeutic options for digital ulcers in patients with systemic sclerosis. J Dtsch Dermatol Ges 2007;5:460-5.

11. Moinzadeh P, Hunzelmann N, Krieg T. Combination therapy with an endothelin-1 receptor antagonist (bosentan) and a phosphodiesterase $\mathrm{V}$ inhibitor (sildenafil) for the management of severe digital ulcerations in systemic sclerosis. J Am Acad Dermatol 2011;65:102-4

12. Austin MJ, McDougall NI, Wendon JA, Sizer E, Knisely AS, Rela M, et al. Safety and efficacy of combined use of sildenafil, bosentan, and iloprost before and after liver transplantation in severe portopulmonary hypertension. Liver Transpl 2008; 14:287-91.

13. Catapano-Minotti G, Corsonello A, Guadalupi G, Spani R, Antonelli-Incalzi R. Treatment of severe pulmonary hypertension secondary to scleroderma: A three-drug approach. Intern Med 2008;47:511.

14. Konstantinos G, Petros P. Phosphodiesterase-5 inhibitors: Future perspectives. Curr Pharm Design 2009;15:3540-51.

15. Wells PS, Anderson DR, Bormanis J, Guy F, Mitchell M, Gray L, et al. Application of a diagnostic clinical model for the management of hospitalized patients with suspected deep-vein thrombosis. Thromb Haemost 1999;81:493-7.

16. Nurnberg HG, Hensley PL, Lauriello J, Parker LM, Keith SJ. Sildenafil for women patients with antidepressant-induced sexual dysfunction. Psychiatr Serv 1999;50:1076-8.

17. Wells PS, Anderson DR, Bormanis J, Guy F, Mitchell M, Lewandowski B. SimpliRED D-dimer can reduce the diagnostic tests in suspected deep vein thrombosis. Lancet 1998;351:1405-6.

18. Heijboer H, Büller HR, Lensing AW, Turpie AG, Colly LP, ten Cate JW. A comparison of real-time compression ultrasonography with impedance plethysmography for the diagnosis of deep-vein thrombosis in symptomatic outpatients. N Engl J Med 1993;329:1365-9.

19. Lennox AF, Delis KT, Serunkuma S, Zarka ZA, Daskalopoulou SE, Nicolaides AN. Combination of a clinical risk assessment score and rapid whole blood D-dimer testing in the diagnosis of deep vein thrombosis in symptomatic patients. J Vasc Surg 1999;30:794-803.

20. Kearon C, Ginsberg JS, Douketis J, Crowther M, Brill-Edwards P, Weitz JI, et al. Management of suspected deep venous thrombosis in outpatients by using clinical assessment and D-dimer testing. Ann Intern Med 2001;135:108-11

21. Ahmed HA, Nadan A, Mohammed MA. Evaluation of chemopreventiv response of pentoxiphylline and sildenfil in colorectal carcinoma experimentally indued in rats: Comparative study with 5-Fluorouracil. Int J Pharm Pharm Sci 2015;7:217-22.

22. Wells PS, Anderson DR, Bormanis J, Guy F, Mitchell M, Gray L, et al. Value of assessment of pretest probability of deep-vein thrombosis in clinical management. Lancet 1997;350:1795-8.

23. Kovacs MJ, MacKinnon KM, Anderson D, O'Rourke K, Keeney M, Kearon $\mathrm{C}$, et al. A comparison of three rapid D-dimer methods for the diagnosis of venous thromboembolism. Br J Haematol 2001;115:140-4.

24. Nurnberg HG, Hensley PL, Heiman JR, Croft HA, Debattista C, Paine S. Sildenafil treatment of women with antidepressant-associated sexual dysfunction. JAMA 2008;300:395-404.

25. Cohen AT, Agnelli G, Anderson FA, Arcelus JI, Bergqvist D, Brecht JG, et al. VTE impact assessment group in Europe (VITAE). Venous thromboembolism (VTE) in Europe. The number of VTE events and associated morbidity and mortality. Thromb Haemost 2007;98:756-64.

26. Eguchi Y, Takahari Y, Higashijima N, Ishizuka N, Tamura N, Kawamura $\mathrm{Y}$, et al. Nicorandil attenuates FeCl-induced thrombus formation through the inhibition of reactive oxygen species production. Circ J 2009;73:554-61

27. Miyhir KP, Kiranjk C, Anta AM. Role of nitric oxide(NO) in capsaicin mediated anti-platelet activity in In vitro, In vivo, Ex-vivo nodel of platelet agreggation assay and artterial thrombosis in rat: Potential therapeutic target? Int J Pharm Pharm Sci 2018;10:44-8. 